\title{
Field study method for indoor air of linear underground facilities
}

\author{
Kirill Lushin ${ }^{1, *}$, Natalia Plyushchenko ${ }^{1}$, Aleksey Ananyev ${ }^{2}$ \\ ${ }^{1}$ Moscow State University of Civil Engineering, 129337, Moscow, Yaroslavskoye sh., 26, Russia \\ ${ }^{2}$ Russian Academy of Architecture and Construction Sciences (NIISF RAASN), Russia
}

\begin{abstract}
The article describes the approach to the organization of field studies of air and thermal regime of underground structures on the basis of experiments carried out in the underground channels with sufficient maintenance.
\end{abstract}

\section{Introduction}

Modern cities are complex system with comprehensive relations between all of its components. In everyday practice it is ordinary to meet high requirements to such factors as urban space using efficiency, enhancement of safety level, meeting the ecological requirements and introduction of energy-saving technologies. Enhancement of usage efficiency of urban space is impossible without enhancement of underground facilities network. Among them the transport as well as communication engineering tunnels play a special part.

Underground facilities and indoor air quality is a well-known field for researches in Moscow state University of Civil Engineering [1,2]. For many years there were field and theoretical researches for different issues in design, construction and maintenance of city tunnels, metro stations, communication channels and so on.

History of global construction and maintenance of such objects has many decades. The number and length of these objects confirms its importance in terms of sustainable development of cities as well as a budget planning for promotion and enhancement of urban functionalities. Improving of energy efficiency of exploitation of urban underground facilities can be a significant reserve of power service at regional and national level. In that context the Moscow engineering stuff from different relevant organizations works towards to optimization and introduction of innovative solutions and scientific justification of reallife experience in construction area as well as service of tunnel for different purpose, different type and varied placement depth $[1,2]$. In addition, scientists from the Department of Heating and Ventilation (MGSU, Moscow) carry out theoretical investigations in field of air-thermal conditions of underground facilities. Specific of the last studies is active application of math modeling with using of computer-assisted numerical experiment for building information model (BIM) [3, 4]. For verification of earlier data and correction of further research process some of field studies in Moscow underground buildings is realized.

* Corresponding author: LushinKI@mgsu.ru 
The main problem solved by tunnel ventilation system is keeping the air-thermal and gas balance inner space at acceptable level for operating equipment and networks as well as providing of required hygiene and sanitary conditions and safety of staff during revising and work performance. Environment disadvantages influenced on air-thermal and gas balance of the building can be followings: increased and decreased humidity as well as inner temperature and gas accumulation. Herewith the some factors are connected each other's and some factors are incompatible. Thus, solving the problem of gas accumulation in inner space of underground facility by ventilation the negative factor is replaced by others followings factors: increased or decreased air temperature, excess moisture and gas accumulation from exhaust of automobile transport. Efficiency of the tunnel ventilation system could be estimated according to intensity of reduction of influence of negative factors with length of tunnel on distance between plenum ventilation chamber and exhaust shaft. Theoretically it is possible to estimate the efficiency of tunnel ventilation on the base of temperature and humidity data as well as air gas composition. Actually, one of the affordable methods for field study is indirect assessment of ventilation system activity according to temperature factor.

\section{Field study method for indoor air of linear underground facilities}

As instrument for investigations was used the hardware-software complex on the base of network of autonomous compact programmed temperature registers Testo 174 -type, highperformance laptop with special software.

Also laboratory machine consists of elements of wire edge to connection with registers as well as package consisting of multi-function apparatus testo 435-4 providing with replaceable probes to measure parameters of temperature, humidity and air movement as well as temperature of solid surface. Working plan supposes subsequent uniform placement of temperature registers along the tunnel length in area from supply grill of ventilation system to input terminal into air flue for a long period of time. Depending of dynamic properties of air-thermal tunnel conditions it is possible the preprogramming of measurement and data recording for different period of time. So, as optimal value of measurement time period for most parts of studies the 3-minute period is used. In this case the register memory size is enough for data recording in non-stop regime during a week. It should be noted the part of data redistricted with equipment in initial and final time period of experiment can be ignored when its analysis due to interferences caused by human factor. All registers when programming was synchronized to each other in time, measurement time period as well as form of data recording.

As study subject the some typical tunnels from different regions of Moscow city are chosen. Among studied objects the facilities with long service history such as tunnels putted into service 3-4 years ago as well as deep placement tunnels are investigated. The special attention is paid to introduction of tunnels with operational heat network as well as only with communication and power cables. Also there are tunnels built by cut-and-cover and shield-driven tunnels [6, 7]. Studies of air-thermal conditions and efficiency of ventilation system are realized for all seasons during a year. All studied objects are in working condition. They are applied regularly and supplied with followings: connection system as well as fire and security signal system; emergency illumination; batch-type plenum mechanical system. Aspiration from tunnels is accomplished naturally as well as by plenum ventilation system.

Activation of ventilation system was realized regularly by engineering staff according to the following regime: an hour in the morning before work day; an hour in the evening after work day. During the study the regime was stable. In case of necessity of realization of large-scale works the opportunity to activate a ventilation system any time and during any 
time period was organized. During all the experimental period the tunnels normally worked without remedial maintenance, emergencies and failures in operation. It should be noted the technical state of the studied buildings is at high quality level [5] due to the «Moskollektor» company support.

Operational service works efficiently keeping in good order and in a hygienic condition. The strong access mode and safety compliance control onsite is supplied. Technical staff takes required training in area of the studied parameters of air-thermal conditions. The above factors significantly influent on quality and quantity of the data obtained. Partial results are presented in earlier study reports $[8,9]$.

In Fig. 1 the results of analysis of network register data from the tunnel Grazhdansky obtained for a month (May-June) are presented. Durability of measurement is $3 \mathrm{~min}$. On yaxis the temperature data are presented. L8-register is placed outside in shaded place near the one of the air-intake shafts. L6-register is placed on cable cantilever in height-middle zone in the middle of the tunnel length. L5 and L7-registers are placed in the same crosssection in top and bottom zones of tunnel, respectively. L1, L2, L3, L4-registers are equally spaced in top of tunnel zone from pull-out shaft to plenum shaft. In Fig. 2 the placement of registers along the tunnel is shown schematically. In Fig. 3 the example of placement of one of registers of top tunnel zone is presented. In Fig. 1 we can see variation of air temperature in controlled points vs. external air temperature. Also we can observe regular activation of mechanical ventilation system, especially in the morning before work day. Best of all the moment of ventilation system activation is fixed by L4-register (that is next to inflow chamber).

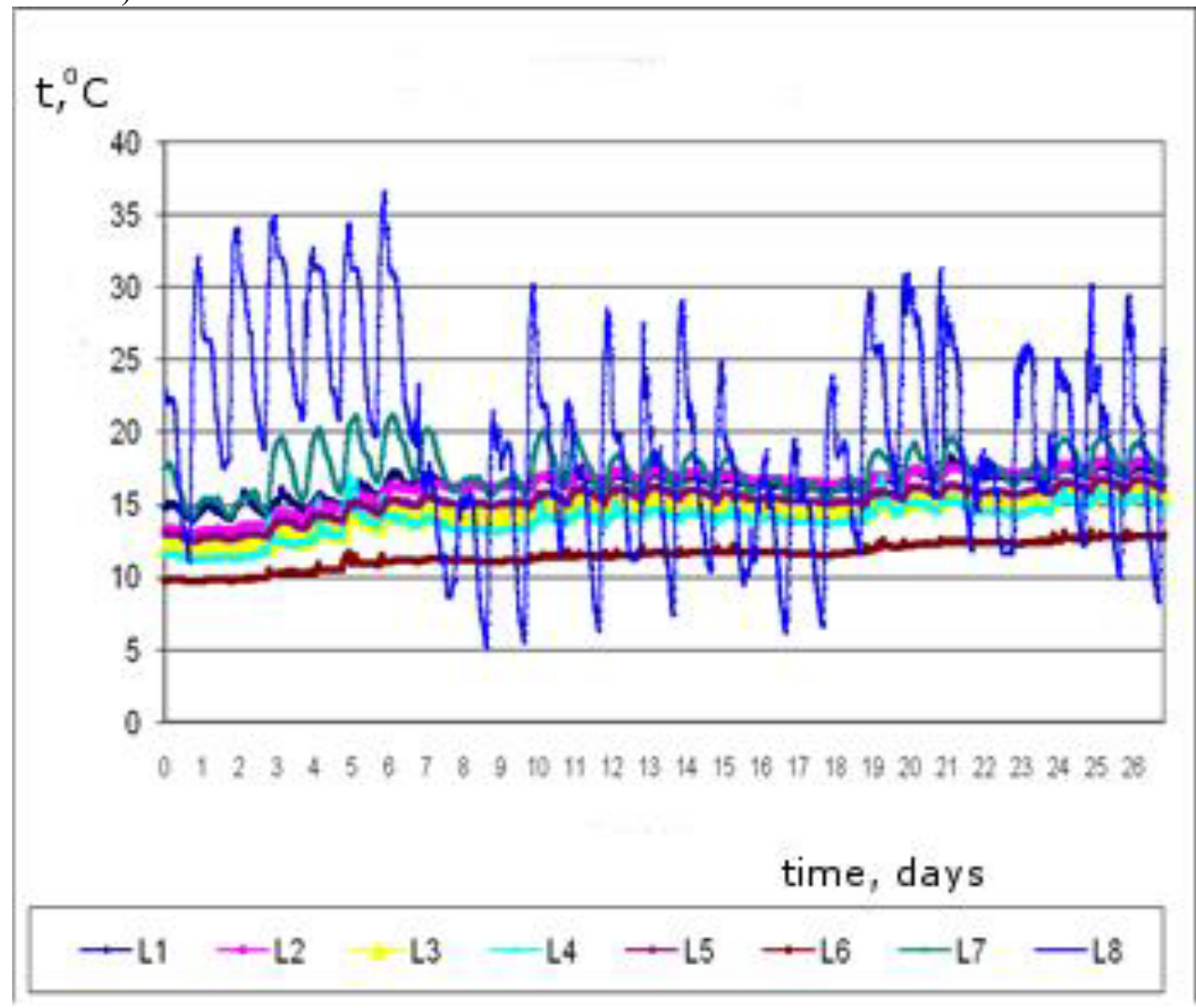

Fig. 1 Variation of air temperature in the tunnel Grazhdansky from 25.05.2007-21.06.2007, 1. Temperature, ${ }^{\circ} \mathrm{C} 2$. Days 


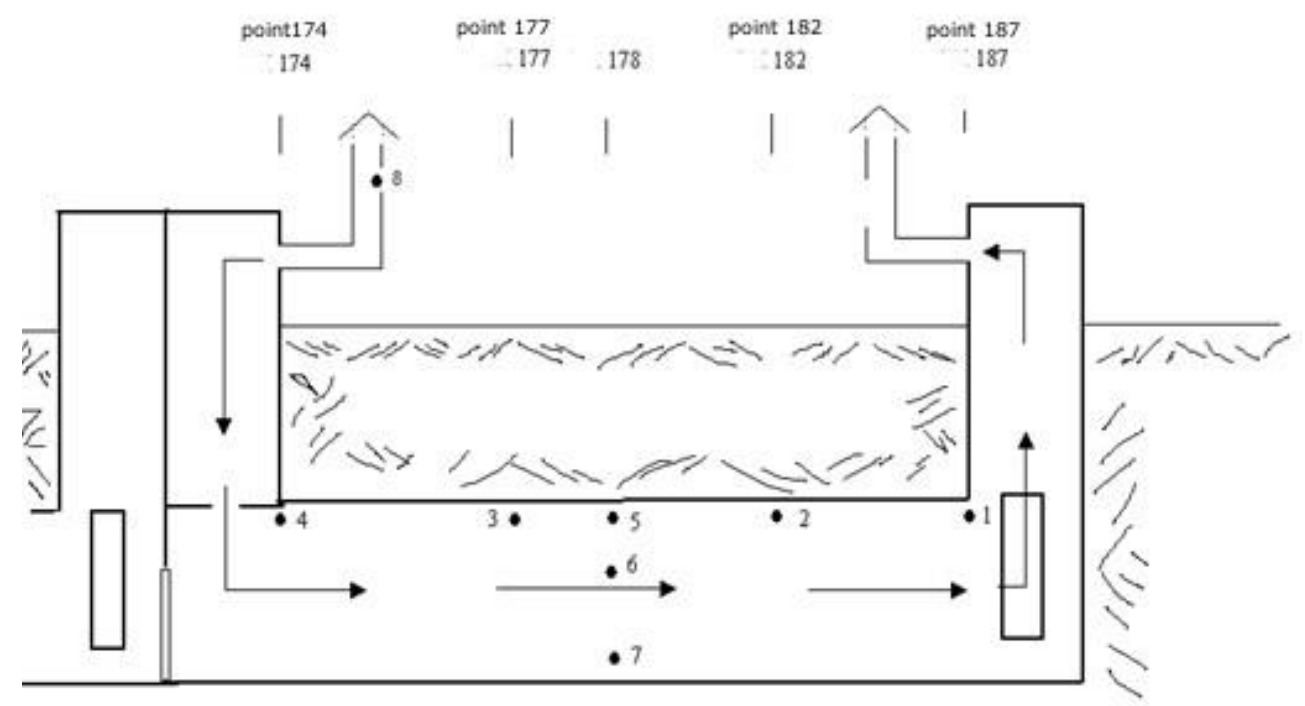

Fig. 2 Scheme of the sensor placement

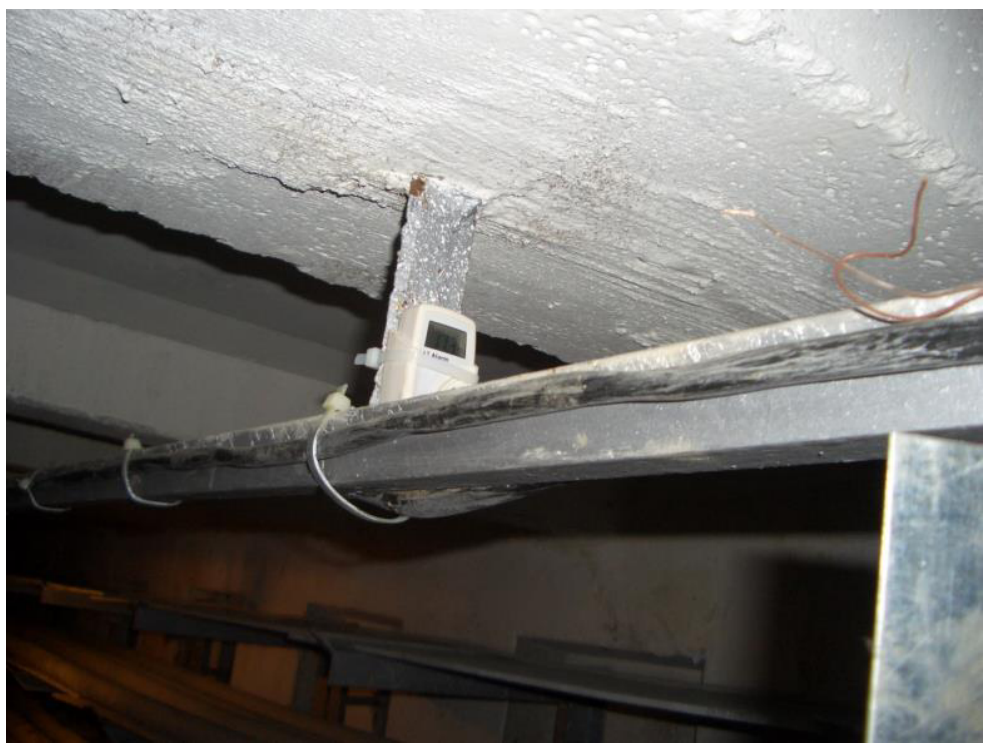

Fig. 3 Placing the sensor at one of the measuring points.

Registers placed far from an inflow chamber fix weak variations of air temperature at the same moment. It can point out that the air when moving along a tunnel is heated as well as the efficiency of ventilation system is not acceptable to provide air exchange throughout the length of regular section of underground building. L6-register quite expressively fixes the peaks of evening increased loads on electrical cable, placed in tunnel. L2-register is placed in the warmest zone of tunnel. Its values are always 1-1.5 higher than others analogous. According to Fig. 1 irregular temperature variation of external air as well as irregular activation of ventilation system significantly influent on data of underground apparatus. 


\section{Conclusion}

The presented analytic method allows accumulation of wide base of results of field measurement for linear underground buildings of different type. At present time a correction of earlier applied mathematical models [10] for further improvement of theoretical base for engineering investigations and standardization when design and performance of the work when construction of underground buildings is realized. The developed method allows highly-accurate qualitative monitoring of environment and heat conditions of buildings for different purpose [11-12] and with different properties. Hardware system is easily scaled and adapted for specific engineering tasks. Accumulated experience allows quickly analyzing the measured results as well as estimation and forecasting of air-thermal conditions of buildings and constructions.

\section{References}

1. E.V. Kaznin, Preceedings 52. Heating and ventilation 1, 102-108 (1967)

2. E.V. Kaznin, Water-supply and sanitary engineering 4, (1966)

3. E.V. Korolev, V.A. Smirnov, Advanced Materials Research 746, 277-280 (2013)

4. A. Volkov,A. Sedov, P. Chelyshkov, E. Kulikova, Applied Mechanics and Materials 584-586, 761-764 (2014)

5. N. Makisha, E. Gogina, Applied Mechanics and Materials 587-589, 644-647 (2014)

6. V. Gagarin, A.Y. Neklyudov, International Journal for Housing Science and Its Applications 39 (2), 79-87 (2015)

7. V. Orlov, A. Andrianov, Applied Mechanics and Materials 580-583, 2398-2402 (2014)

8. Research report, Stage 2, MGSU (2007)

9. Research report, Stage 3, MGSU (2007)

10. Y.Y. Kuvshinov, A.G. Rymarov, Proceedings 1, 22-25 (2003)

11. Y. Kharkin, E. Korol, A. Davidyuk, Procedia Engineering 117 (1), 172-178 (2015)

12. V. Gagarin, V. Kozlov, K. Lushin, International Journal of Applied Engineering Research 10(23), 43438-43441 (2015) 